\title{
REFLEXÕES SOBRE O SURGIMENTO DA ARTE BARROCA NA ITÁLIA E SUA EXPANSÃO PELAS REGIÕES DE ANTUÉRPIA E HOLANDA
}

\author{
REFLECTIONS ON THE ARISE OF BAROQUE ART IN ITALY AND ITS EXPANSION \\ THROUGH THE REGIONS OF ANTWERP AND NETHERLANDS
}

\section{Selvita Maria de Paula}

RESUMO: O presente artigo tem o propósito de refletir sobre $\mathrm{O}$ surgimento da Arte Barroca na Itália e sua expansão pelas regiões da Antuérpia e Holanda, no início do século XVII. O tema é importante porque ocupa um relevante espaço na cultural mundial e pode vir a despertar um olhar crítico e estético da Arte Barroca, como por exemplo, na pintura, na escultura, na arquitetura, entre outros, contribuindo para ampliar conhecimentos de mundo, provocando o espírito pesquisador que existem em todo ser humano. Alguns autores foram aportes teórico, como: Ernst Gombrich (2018); H.W. Jason (200I); Graça Proença (2007); Myriam Oliveira (2014), dentre outros. Nesse sentido, esse artigo tem o objetivo de aguçar o espírito investigativo do observador da Arte Barroca.

Palavras-chave: Barroco. Arte italiana. Expansão. Antuérpia. Holanda.

ABSTRACT: This article aims to reflect on the emergence of Baroque Art in Italy and its expansion through the regions of Antwerp and Holland, in the start of the itth century. The theme is important because it occupies a relevant space in the world culture and can awaken a critical and aesthetic look of Baroque Art, such as in painting, sculpture, architecture, among others, contributing to expand the knowledge of the world, provoking the research spirit that exists in every human being. Some authors were theoretical contributions, such as: Ernst Gombrich (2018); H.W. Jason (200I); Graça Proença (2007); Myriam Oliveira (2014), among others. In this sense, this article aims to sharpen the investigative spirit of the observer of Baroque Art.

Keywords: Baroque. Italian art. Expansion. Antwerp. Holland.

\section{INTRODUÇÃO}

O presente artigo apresenta reflexões sobre a Arte Barroca na Itália, no início do século XVII e sua expansão pelas regiões de Antuérpia e Holanda.

O termo "Barroco" significa em espanhol, pérola defeituosa e assim foi chamado, como crítica, por aqueles que não aceitavam o fato de que esse estilo de arte havia rompido com o equilíbrio entre sentimento e razão, tão ao gosto da cultura clássica da época. Os artistas renascentistas procuravam estabelecer o diálogo entre ciência e arte, diferente do Barroco que primava pela emoção em detrimento da razão.

O interesse pelo tema está ligado ao fato de que a Arte Barroca ocupa um relevante espaço na cultura mundial, seja na pintura, escultura, arquitetura e outros. 
Esse trabalho terá como objeto de estudo a Arte Barroca contextualizando o início deste movimento artístico na tália e sua expansão pelas regiões de Antuérpia e Holanda.

Para a realização deste estudo foram usados aportes teóricos de autores, como: Ernst Gombrich (2018); H.W. Jason (200I); Graça Proença (2007); outros, considerando suas grandes contribuições para o estudo das artes.

Conhecer a Arte Barroca contribui para ampliar os conhecimentos e ajudar o educando construir uma visão mais aguçada do mundo que o cerca, despertando um olhar crítico e estético das Artes Visuais.

Este trabalho está organizado em dois momentos. Inicialmente aborda a historicidade da Arte Barroca na Itália e seus principais representantes e obras. Em seguida, fala da expansão do movimento barroco pelas regiões de Antuérpia e Holanda, bem como sua nacionalização pelos artistas daquele período.

Espera-se que esse estudo sobre o Barroco provoque o espírito investigativo, pesquisador e observador que existe dentro de todo ser humano e com mais ênfase nos professores que atuam nas diversas linguagens da Arte.

\section{O SURGIMENTO DA ARTE BARROCA NA ITÁLIA NO INÍCIO DO SÉCULO XVII}

O Barroco, nascido na Itália no final do século XVI e início do Século XVII, é um estilo de arte com características próprias, que foi dominante no período de 1600 - 1750 . Há controvérsias se esse estilo, o barroco, é ou não, a última fase do Renascimento.

A palavra barroco é originária do espanhol "barrueco", que significa um tipo de pérola com formação defeituosa, foi um termo pejorativo usado para definir esse estilo de arte como grotesco, extravagante, exagerado e que não observava as regras estabelecidas pelo classicismo. Para Gombrich (2018, p. 293): "O termo "barroco" foi empregado pelos céticos de um período posterior, contrários às tendências do século XVII, com o intuito de ridicularizá-las". Os artistas da renascença procuravam o equilíbrio entre sentimento e razão e entre arte e ciência e veio o estilo barroco e a emoção predominou sobre o racionalismo.

A arte barroca aconteceu num período em que a Europa vivia o início de governos absolutistas, onde o Rei representava Deus na terra, a revolução comercial que fortalecia a classe burguesa e também a Reforma Protestante a qual estava ocasionando muitas perdas de receitas para a Igreja Católica. Martinho Lutero, uma das figuras centrais da Reforma Protestante, era um monge agostiniano que discordou do que considerou desmando da Igreja. Nascimento; Giraldi; Duete (2013, p. 254), afirmam que:

Lutero era Doutor em Teologia e Doutor em Bíblia, estudou em profundidade as escrituras e quanto mais estudava, mais percebia a distancia que a igreja estava da verdade. Incomodado, escreveu as "95 teses" em que pedia esclarecimentos sobre a venda das indulgências na qual os fiéis acreditavam terem seus pecados perdoados pelas contribuições e pelas obras.

Com essa postura de Lutero e outros que defendiam a Reforma, a Igreja Católica organizou a Contra-Reforma, usando a arte para divulgar o catolicismo e influenciar pessoas. Afirma Oliveira (2014), que o barroco religioso é conhecido também como "Arte da Contrarreforma" por vir de encontro aos ideais e estar adequado a esse movimento de renovação da Igreja Católica, respaldada pelo Concílio de Trento (1545 - 1563). Foi um extraordinário feito, já que a meta era se opor à Reforma Protestante e simultaneamente a 
conquista missionária dos povos americanos desvendados pelos portugueses e espanhóis em suas conquistas pelo mar.

Lutero lutou em defesa do conhecimento, incentivando a alfabetização para que todos pudessem ler a bíblia, traduziu-a para o alemão e disponibilizou seus trechos a quem quisesse. Diante de tal situação, a igreja inicia a Contrarreforma para fortalecer a autoridade da fé católica e sua expansão. De acordo com Nascimento; Giraldi; Duete (2013, p. 255), aconteceu que:

Nesse contexto, iniciou-se a Revolução Comercial, com os objetivos de fortalecer a igreja e de enriquecer o Estado. A igreja, pela Contrarreforma, apoiava reinados e burgueses, concedendo-lhes poder e regalias. $\mathrm{O}$ rei, tendo o poder concentrado em suas mãos, compensava o clero e a nobreza, apoiando-as.

Depois da divisão dos países baixos, pelo absolutista católico Rei Filipe II, as províncias do sul ficaram com o catolicismo e a do norte (atual Holanda) com o protestantismo. Nos países que se mantiveram católicos, a igreja usou a arquitetura, pintura e escultura para ostentar seu poder. É importante ressaltar que os príncipes que deram apoio ao crescimento da arte barroca estavam interessados em demonstrar seu poder, sem muita preocupação com a religiosidade. Segundo Janson (200I, p. 716):

Por volta de i6oo, Roma tornou-se a fonte principal do barroco, tal como fora o Renascimento Pleno um século antes, chamando a si artistas de outras regiões para a realização de novas e ousadas tarefas. O papado patrocinava a arte em larga escala, com vista a fazer de Roma a mais bela cidade do mundo cristão, "para maior glória de Deus e da Igreja".

Já no a no de 1585 , a igreja havia começado uma campanha para atrair novos talentos para Roma. Os artistas de outras regiões chegavam para a realização de novas e ousadas tarefas porque os que estavam em Roma eram considerados maneiristas tardios de fraco talento. Não demorou muito e jovens mestres ambiciosos chegaram em Roma, foram eles que criaram o novo estilo com seu talento e genialidade.

Neste contexto, houve grande fermentação no mundo das artes na Itália. A pintura, a escultura, a arquitetura, entre outras, se destacaram mostrando ao mundo um novo estilo chamado Barroco, o qual apresentava características próprias, como diagonalidade, cor e luz, movimento, dramaticidade, curvas e contracurvas, elementos retorcidos, espirais, colunas torsas, teto elevado, etc., optando por composições mais complexas, desdobrando-se nos temas religiosos, na vida da nobreza e também na vida do povo simples. Alguns pintores se destacam de forma marcante na península Itálica, destacaremos Caravaggio e Carracci, que eram protagonistas nas discussões acaloradas sobre arte naquela época, afirma Gombrich (2018, p. 297):

Um era Annibale Carracci (156o - 1609), de Bolonha, o outro, Michelangelo da Caravaggio (1573 - 16ro), de uma cidadezinha próxima a Milão. Ambos pareciam cansados do Maneirismo; os caminhos escolhidos por cada um para ultrapassar seus rebuscamentos, porém, foram distintos.

Estudiosos da arte veneziana e de Correggio, Annibale Carracci, ao chegar em Roma apaixonou-se pelas obras de Rafael. Procurou resgatar sua beleza imitando a arte clássica mas com apelo emocional, característica da arte barroca. Como afirma Jason (200I, p. 720), sobre Annibale Carracci: "Entre 1597 e 1604, produziu a sua obra mais ambiciosa, o afresco do teto na Galeria do Palácio Farnese, que em breve se tornou quase tão famoso como os afrescos de Michelangelo e Rafael". Neste trabalho, Carracci mostra sua habilidade e 
exuberância artística, a qual o distingue da arte do maneirismo e do Renascimento Pleno. Ele não foi exatamente um revolucionário, mas antes um reformador, usava estilos da are do norte e do sul com um toque dos clássicos, mas deu mais vitalidade ao seu trabalho, o que tornou um dos grandes artistas do movimento barroco na Itália.

Caravaggio, homem de gênio indomável, temperamento forte e irascível, teve seu trabalho caracterizado pela forma revolucionária com que usa a luz em suas pinturas. Ele queria repensar a arte, não aceitava a "beleza ideal" defendida pelos clássicos, seu compromisso era com a verdade. Procurava seus modelos entre as pessoas do povo. Para muitos de seus críticos, o objetivo do artista era chocar o público e o apelidaram de "naturalista” para expressar tal manifestação. O fato é que, segundo Gombrich (2018, p. 299): O "naturalismo" de Caravaggio, isto é, sua intenção de reproduzir a natureza de forma fiel, quer a consideremos feia ou bela, era talvez mais devota que a ênfase de Carracci na beleza. Caravaggio deve ter lido a Bíblia várias vezes, e refletido sobre suas palavras. Era um desses grandes artistas, como Giotto e Dürer ante dele, que queria ver os acontecimentos sagrados com seus próprios olhos, como se estivessem acontecendo na casa ao lado - e fazia todo o possível para tornar mais reais e tangíveis os personagens dos textos antigos. Até mesmo seu modo de lidar com luz e sombra contribui para tal propósito: em vez de conferir leveza e suavidade ao corpo, sua luz é dura e quase ofuscante no contraste com as sombras profundas.

Caravaggio pintou obras extraordinárias, entre elas, está “A vocação de S. Mateus”, destinada para a capela da Igreja de S. Luigi dei Francesi, entre outras, como enfatiza Jason (200I), seus quadros tem um "cristianismo laico" isento dos dogmas da igreja católica, com um "naturalismo" que encanta a todos sem distinção. Essa qualidade de Caravaggio acabou influenciando os protestantes também, pois, conseguia retratar os personagens bíblicos com feições bem humanas, como se fossem pessoas comuns. Por volta de i6o5, outros artistas começaram pintar seu estilo, dentro e fora do território italiano.

A pintura em tetos de igrejas teve um destaque especial na arte barroca como por exemplo, o trabalho do artista italiano Andrea Pozzo (1642 - 1709), ele era decorador, arquiteto, cenógrafo, pintor, professor, outros, o qual pintou o famoso afresco "A glória de Santo Inácio”, (1691 - 1694), no teto da igreja de Santo Inácio, em Roma. Como afirma Proença (2007, p. 137), “A obra impressiona pelo número de figuras e pela ilusão - criada pela perspectiva - de as paredes e colunas da igreja continuam no teto, e de que este se abre para o céu, de onde santos e anjos convidam os homens para a santidade”. Como Guido Reni; Guernico, entre outros, também ficaram famosos por seus afrescos pintados em tetos de igrejas.

Suas obras são célebres, causam encantamento nos observadores e amantes da arte barroca e respeito aos que preferem outros estilos.

Além da pintura, a arquitetura e a escultura foram usados como valiosos instrumentos pela igreja católica para ostentar seu poder e divulgar a vida espiritual para os fiéis. A arquitetura é usada para criar um espaço acolhedor para os fiéis, onde pudessem ter sentimento de pertença e envolvimento com a igreja.

Essa suntuosa arquitetura realizou-se no século XVII, principalmente nos palácios e igrejas. Para Proença (2007, p. 139):

Na Itália, por exemplo, a praça de São Pedro (1657 - 1666), projetada por Bernini, a igreja Sant'Agnes (1653 - 1657), por Barromini, e a igreja Santa Maria della Pace (1656 - 1657), por Pietro da Cortana, ilustram de modo significativo essa vitória da igreja católica. Por outro lado, governantes como Luís XIV da França, que se 
consideravam reis por direito divino, também desejaram palácios que demonstrassem poder e riqueza.

Grandes artistas se destacaram nesse contexto. Entre eles, o taliano Gian Lorenzo Bernini ( 1598 - I680). Bernini é considerado o arquiteto - escultor do seu século. O artista barroco mais completo, pois foi arquiteto, urbanista, escultor, decorador, pintor, outros. Algumas de suas obras serviram de elemento decorativo nas igrejas como o Baldaquino (I624 - i633) da basílica de São Pedro, no Vaticano, sendo considerada a primeira obra totalmente com estilo barroco, medindo 29 metros de altura, impressiona pela grandiosidade e a cadeira de São Pedro, que também é uma obra majestosa do artista. Segundo Jason (200I, p. 730):

Quando desenhava o Trono de São Pedro, Bernini delineou também como "decoração exterior", a magnífica praça em frente de S. Pedro, a qual serve de imenso átrio, emoldurada por colunatas que o próprio artista comparou aos braços maternais da igreja. A basílica, integrada num cenário grandioso de espaço "modelado", só pode ser comparada em importância ao antigo santuário romano de Palestrina.

Bernini, projetou na construção da Piazza de San Pietro, no Vaticano, diferentes efeitos visuais desenvolvendo a colunata, ele mudou a estrutura visual da Brasília de São Pedro. Suas obras: O êxtase de Santa Tereza (1645-52); Davi (I623), entre outras, também são extraordinárias, apresentando o talento grandioso desse artista.

$\mathrm{Na}$ arquitetura, Bernini tinha um rival. Seu nome era Francesco Barromini (15991667), o qual tinha uma personalidade instável e reservada. Ao contrário de Bernini que era um homem do mundo, expansivo e autoconfiante. O contraste entre os dois temperamentos também existiu na arquitetura. Ressalta Jason (200I, p. 731) que “Ambas representam o apogeu da arquitetura barroca em Roma, mas enquanto o projeto de Bernini para a colunata

de São Pedro é de uma unidade impressionantemente simples, as estruturas de Barromini são extravagantemente complexas". Barromini usava as ondulações e as formas distorcidas com o objetivo de dar à construção uma estrutura em constante movimento. Estilos diferentes, porém ambos grandiosos e inovadores que mudaram a arquitetura urbana da época.

\section{A EXPANSÃO DO MOVIMENTO BARROCO NAS REGIÕES DE ANTUÉRPIA E HOLANDA}

O Barroco se expandiu pela Europa no século XVII até a primeira metade do século XVIII em vários países. Em alguns, acabou absorvendo o nacionalismo, como por exemplo, podemos citar os países baixos. Proença (2007, p. 142) ressalta que:

Nos Países Baixos, o Barroco desenvolveu-se em duas grande direções, sobretudo na pintura. Na região hoje correspondente à Bélgica, caracterizou-se por linhas movimentadas e forte expressão emocional. Já na Holanda, ganhou aspectos mais próximos do espírito prático e austero do provo Holandês.

Peter Paul Rubens (I577-I640) artista Hamengo, foi um dos pintores de maior sucesso na Europa. Representante do Barroco, é conhecido por seu estilo extravagante que enfatiza movimento, cor e sensualidade em sua obra. Conhecido por seu temperamento dócil e diplomata, foi educado na fé católica e levava a vida pautada nos princípios da igreja e falava seis idiomas. Rubens usava o pincel com maestria. Usando luz, cor, curvas, diagonais e composições em espiral em suas obras, emocionando o expectador porque, como afirma 
Gombrich (2018, p. 306), com suas pinceladas Rubens podia insuflar vida em qualquer coisa, ressaltando que:

Foi a combinação de seu talento impar para grandes composições em cores e seu dom para difundi-las de vigorosa energia que granjeou a Rubens um nível de fama e sucesso que nenhum pintor alcançara antes. Sua arte era tão apropriada para incrementar a pompa e o esplendor dos palácios e glorificar os poderes deste mundo que ele praticamente monopolizou esse território.

Ainda segundo o autor, na página 304, enquanto as obras dos pintores de Flandres eram de pequenas proporções, Rubens trouxe da Itália a preferência por telas bem grandes, com a finalidade de decorar igrejas e palácios, atendendo a demanda de dignitários e príncipes daquela época em diversos países. Aos 31 anos de idade, voltou para Antuérpia. Ele chegara em Roma em i6oo com 23 anos de idade para estudar as obras antigas e novas da Itália. Foi sempre um ávido estudioso em várias cidades, como Roma, Gênova e Mântua. Apreendeu tudo que havia para aprender, acrescentando mais luz, mais espaço, mais movimento, mais cor e uma vivacidade alegre, festiva, que caracterizou suas pinturas e as tornavam ímpares usando cores fortes. Como era de costume na pintura flamenga, Rubens usava cores fortes e quentes, como firma Proença (2007, p. 143):

Em seus quadro, é geralmente no vestuário que se localizam as cores mais fortes o vermelho, o verde e o amarelo -, que contrabalançam a luminosidade da pele clara das figuras humanas, como $\mathrm{O}$ rapto da filha de Leucipo, Caçada de leões e Helena Fourment com seu filho Francis. Uma das telas mais coloridas de Rubens é O Jardim do amor. Trata-se de uma cena em que realidade e alegoria se fundem.

As pinturas de Rubens apresentam linhas movimentadas e forte carga emocional, destacando cenas com corpos de linhas contorcidas e roupas com pregas que simulam grande movimento, dando a obra uma vivacidade que impressiona o observador, devido ao amor à vida que imprimia em suas pinturas.

Van Dyck, foi o único artista do barroco flamengo que conseguiu fama internacional. Discípulo de Rubens e 22 mais jovens, tornou-se exímio retratist. Segundo Jason (2001, p. 747):

Anthonny Van Dyck (1599-164I) foi essa raridade entre pintores, um menino prodígio. Antes dos vinte anos, tornara-se já o ajudante preferido de Rubens. Mas faltava-lhe a vitalidade e a imaginação do velho mestre, e a sua fama veio-lhe sobretudo dos retratos, especialmente os que executou na Inglaterra, como pintor da corte de Carlos I, entre i632 e i64I. Entre os mais belos conta-se o de Carlos I na Caça.

Van Dyck renovou o retrato da corte maneirista. Criou uma nova tradição do retrato aristocrático. Colocava seus modelos em cenários refinados, alongava suas silhuetas para parecem mais elegantes e esbeltos. Com esse talento para retratar a aristocracia, tornouse o preferido da corte de Carlos I na Inglaterra até finais do século XVIII. Seu trabalho influenciou outros artistas no continente.

$\mathrm{Na}$ Holanda, a pintura barroca assumiu uma tendência mis descritiva, como afirma Proença (2007, p. I43): "cujos temas preferidos foram as cenas da vida domestica e social, trabalhadas com minucioso realismo", ganhando assim o aspecto do provo holandês, amantes da praticidade e austeridade. De fé protestante, os artistas holandeses não tiveram, como aconteceu em países católicos, encomendas públicas do Estado e da Igreja, o colecionador particular tornou-se o principal suporte do pintor. Jason (2001, p. 748), relata 
que os quadros tinham-se tornando, na verdade, uma mercadoria cujo comercio obedecia às leis da oferta e da procura. Muitos artistas trabalhavam, "para o mercado" e não para clientes individuais.

Ao torna-se independente e protestante, a Holanda era uma nação orgulhosa de seu povo, sua gente e foi neste contexto que surgiram várias escolas transmitindo o estilo Caravaggio a outros mestres holandeses. Neste cenário, surgiu um mestre notável que soube aproveitar a oportunidade, como afirma Jason (200I, p. 750);

Um dos primeiros a aproveitar esta experiência foi Frans Hals (I580-1666), o grande retratista de Haarlem. Nasceu em Antuerpia e o pouco que sabemos de suas primeiras obras sugere a influencia de Rubens. Mas o estilo que veio a desenvolver patente em quadros como $\mathrm{O}$ alegre beberrão, combina a robustez e a amplidão de Rubens com uma concentração no "momento dramático" que só pode ter vindo de Caravaggio, via Antuérpia. Nada foge à espontaneidade: os olhos brilhantes e a boca entreaberta, a mão erguida, o copo de vinho em equilíbrio precário e - ainda mais importante - a rapidez no apontamento das formas.

As pinceladas rápidas e instantâneas de Frans Hals, mais parecem a um esboço se comparada com as pinturas de Rubens. Embora pareçam rápidas suas pinceladas, são apenas ilusão de sua técnica que nasce do seu perfeito domínio do pincel. Qualidades expostas na sua obra Malle Barbe. No final de sua vida, o artista apresenta um estilo emocional severo, como mostra o retrato de grupo As Regentes do Asilo de Velhos de Haarlem, onde as personagens parecem ser o símbolo do sofrimento e da morte. Há que se notar que Hals foi o primeiro mestre ilustre da Holanda livre, por sua originalidade e inovação.

O maior pintor holandês foi Rembrandt Harmenszoom Van Rijm. Além de pintor foi, desenhista e gravurista. Nascido na cidade de Leyden, abandonou os estudos para ser pintor. Para Jason (2001, p. 752):

Rembrandt (I606-ı669), o maior gênio da arte holandesa, sofreu também no começo de sua carreira a influencia de Caravaggio. Os seus primeiros quadros do período de Leyden (1625-1631), são pequenos, fortemente iluminados e intensamente realísticos; muitos deles, como Tobias e Ana com o Cabrito, tratam de assuntos do Antigo Testamento - a Bíblia foi durante toda vida a fonte preferida de Rembrandt. Até este pequeno painel, cheio de pormenores caseiros da vida camponesa, revela qualidades que distinguem as cenas bíblicas de Rembrandt das anteriores; mostra não só um maior realismo, mas uma nova atitude emocional.

Desde o inicio da arte cristã, os episódios da Bíblia eram retratados para ilustrar a doutrina cristã. Mas Reembrandt viu as histórias do Antigo Testamento com o mesmo espírito laico de Caravaggio sobre o Novo Testamento. Como seu quadro O Cegar de Sansão, onde desenvolveu o estilo barroco com perfeição, acentuando o drama da cena violenta que retrata um tempo de muita crueldade e paixão.

Rembrandt Conseguia imprimir realismo e dramaticidade por meio da gradação da claridade de forma genial. Essa qualidade o tornou um dos maiores artistas no domínio da luz. Proença (2007, p. I45), afirma:

O que dirige nossa atenção em seus quadros não é propriamente o contraste entre luz e sombra, mas a gradação da claridade, os meios-tons, as penumbras que envolvem áreas de luminosidade mais intensa. É assim por exemplo, nas telas Mulher no banho, A ronda noturna, A aula de anatomia do Dr. Joan Deyman e Os negociantes de tecidos. Sua pintura mais famosa, porém, é A lição de anatomia do Doutor Tulp. 
Nesta última pintura, o artista usando luz, consegue indefinir figuras e espaços, tornando o ambiente ímpar com as penumbras e luminosidades mais intensas. Gombrich (2018, p. 326), ressalta que "Rembrandt tem tamanha importância em todos os campos da arte holandesa que nenhum outro pintor do período pode ser comparado a ele". Uma de suas façanhas, são os auto-retratos. Reembrandt os pintou desde seus 2I anos até a velhice, o que lhe valeu como biografia, dada a quantidade de obras que produziu sobre si mesmo, registrando cada momento de sua interessante vida.

Vermeer foi um pintor que, ao contrário de seus antecessores, via a realidade singela da vida cotidiana com um olhar só seu, transformando pequenas tarefas domésticas em verdadeiras obras de arte ao pintá-las. Num momento em que os especialistas, mestres, estavam preocupados com os temas, esse artista desbancou essa visão, como afirma Gombrich (2018, p. 328):

O maior desses mestres, Jan Vermeer Van Delft (1632-75), pertencia a geração seguinte à de Rembrant. Consta que era um artista lento e minucioso; não pintou muitos quadros ao longo da vida, e poucos representam uma cena de alguma relevância. Em sua maioria, mostram personagens simples num aposento de uma típica residência holandesa.

Suas pinturas mostram costumes da vida privada holandesa, com personagens simples realizando tarefas rotineiras. Isso acontece em vários de suas obras, como em Moça com brinco de pérolas, a Rendeira, A leiteira, entre outros, onde o artista ressalta a beleza da cena em si, trabalhando cor e luz com maestria. Suas pinturas combinam suavidade e exatidão, tornando-as dignas de serem lembradas. Para Gombrich (2018, p. 329), "É difícil identificar o que faz de pinturas tão singelas e despretensiosas algumas das maiores obras primas de todos os tempos."

\section{CONSIDERAÇÕES FINAIS}

Estas reflexões sobre o surgimento da Arte Barroca na Itália e sua expansão pelas regiões de Antuérpia e Holanda, são de grande importância para ampliar conhecimentos sobre a Arte Barroca e o contexto histórico onde surgiu.

A Base Nacional Comum Curricular (2017), considera que "As Artes Visuais, são os processos e produtos artísticos e culturais, nos diversos tempos históricos e contextos sociais, que tem a expressão visual como elemento de comunicação". Isso possibilita a exploração de múltiplas culturas, inclusive por meio da arte barroca.

O diálogo do ser humano com a arte ajuda-o a entender sua própria história e também deixar seu legado para a posteridade, já que as artes visuais são elementos de comunicação com o passado, o presente e o futuro.

\section{REFERÊNCIAS BIBLIOGRÁFICAS}

BRASIL. Base Nacional Comum Curricular (BNCC). Educação é a Base. Brasília, MEC/CONSED/UNDIME, 2017.

GOMBRICH, Ernst Hans. A História da Arte. Trad. Cristina de Assis Serra. $17^{\underline{a}}$ ed. - Rio de Janeiro: LTC, 2018. 
JANSON, H. W. História Geral da Arte. Trad. Mauricio Balthazar Leal. 2 ${ }^{\underline{a}}$ ed. - São Paulo: Martins Fontes, 200I.

NASCIMENTO, Emerson César; GIRALDI, Fabíola Gonçalves; DUETE, Lizandra Mara Forti Garcia. História da Arte: Da Pré-História ao Barroco. Batatais, SP: Claretiano - Rede de Educação, 2013.

OLIVEIRA, Myrian Andrade Ribeiro. Barroco e Rococó no Brasil. Belo Horizonte: Editora C/Arte, 20I4.

PROENÇA, Graça. História da Arte. São Paulo: Ática, 2007. 